\title{
Core-Periphery Market Failure in the Location of Economic Activity
}

\author{
Miki Malul and Raphael Bar-El *
}

\begin{abstract}
Using a simplified theoretical model, we illustrate the potential existence of a market failure in the location of economic activity, which could lead to an exaggerated concentration in the core region. Based on this, we analyze whether a public policy intervention of decreasing the mobility costs of production factors could lead to the elimination of, or at least a decrease in, the consequences of a market failure. We show that the market failure can be eliminated only when the reduction in mobility costs is made concurrently with changing exogenous conditions in the peripheral regions (such as improvements in infrastructure).
\end{abstract}

Key words: Core-periphery, interregional mobility costs, spatial concentration

JEL Classifications: R12, R13, R41

\section{BACKGROUND}

The geographical concentration of firms is an important factor in both a region's economic development and the income inequality of its residents. The tendency of spatial concentration has been analyzed by many scholars, generally under the global title of the "coreperiphery" issue, and more recently under the theme of the "new economic geography" (see, e.g., Krugman, 1991). Most research has been oriented towards the understanding of free market behavior, however, sometimes including the influence of the public sector as an agent (see, e.g., Bar-El and Schwartz, 2006).

One factor that affects the geographical distribution of firms is the interregional mobility cost of production factors. This concept was introduced in a multiregional model by Krugman (1991) and later in studies conducted by Baldwin (1999), Lanaspa and Sanz (2001a, 2001b), Hu (2002), and Hadar and Pines (2004). In Krugman's model, as well as in later research that extended his model, no distinction is made between the free-market solution and the social optimum. While the free-market solution reflects the optimum for individual firms, the social optimum reflects the gains for the society or the national economy as a whole. The social optimum is expected to reflect the externalities (both negative and positive) that firms create when they decide where to locate. Theoretically, a planner who is able to identify the social optimum might be able to direct a society or the economy to that optimum more efficiently than would a free market. Practically, as we show later, we should also consider the fact that public intervention oriented towards the social optimum may have its own costs that should be taken into consideration.

By permitting capital to be mobile, Baldwin and Martin (2004) find that spatial concentration can occur within Krugman's model, but also that it may be consistent with a process of firms relocating to poor regions. Nonetheless, this is perceived to be a free-market

\footnotetext{
* Malul and Bar-El are, respectively, Lecturer and Professor at the Department of Public Policy and Administration, Ben Gurion University.

Contact author: Miki Malul, Department of Public Policy and Administration Guilford Glazer School of Business and Management, P.O.B 653, Beer Sheva Israel 84000.E-mail: malul@som.bgu.ac.il.

(C) Southern Regional Science Association 2010.

ISSN 1553-0892

SRSA, 1601 University Avenue, PO Box 6025, Morgantown, West Virginia 26506-6025, USA.
} 
process with no relation to the issue of the social optimum. Helsley and Strange (1990), Fujita and Abdel-Rahman (1993), and Dohse (1998) refer to the market failure that results from firms' failures to consider the positive externalities (the marginal influence on the agglomeration advantage) and the negative externalities (the marginal influence on free market prices). Yet these models do not account for the extra social costs associated with these decisions.

Abdel-Rahman and Anas (2004) consider these various perspectives in their analysis of the formation of systems of cities. Still, they conclude that an optimum is not necessarily reached under a free market, thus justifying the intervention of planners. They also show that for different levels of mobility costs, a different optimal solution is reached, considering the optimal solution in the context of the level of specialization of each city in the production.

The present paper does not discuss the details of all of the elements that explain the structure of cities; instead, it delineates the gap between the market optimum and the social optimum in the location of economic activity as a whole. First, we discuss the rationale behind the existence of such a gap; then, we show that the elimination of this gap through public intervention is not always justified.

We first build a simplified model that shows the existence of market failure in the distribution of firms between the core and the periphery when the market is completely free and open. This type of market failure is defined as the difference between the distribution of firms under free-market conditions and the distribution that would lead to the social optimum in terms of the maximization of gains for the society as a whole, as opposed to the maximization of gains for private investors (see Malul and Bar-El, 2009). We introduce the factor of interregional mobility costs and its impact on the gap between a free market and the socially optimal distribution of firms.

The common belief is that lower mobility costs are expected to lead to a greater concentration of economic activity in the core, thus increasing the interregional gap (see Tabuchi and Thisse, 2006). We show that this is not necessarily the case and that a distinction should be made between gaps in economic activity and gaps in the income of the resident population of the regions. In other words, we make a distinction between the gross domestic product in the region (the products produced within the region) and the gross regional product (the products of the population of the region independent of the location of production). Our distinction is similar to that between the gross domestic product (GDP) and the gross national product (GNP) in macroeconomic terms.

\section{THE GENERAL STRUCTURE}

We assume that the objective of the public sector is to maximize the economy's welfare- $R$. For the sake of simplification, we assume that there are only two regions $j$ in the economy. We let Region A be a core region (a region with a high level of economic activity), and $\mathrm{B}$ be a peripheral region. We take this situation as a given in the sense that we do not try to understand the reasons that led to A being a core region from the historical start. We further let the number of firms, $n$, denote the level of economic activity. Hence, by definition, at the start, $n_{\mathrm{A}}>n_{\mathrm{B}}$ where $n_{\mathrm{A}}$ and $n_{\mathrm{B}}$ reflect the number of firms in regions $\mathrm{A}$ and $\mathrm{B}$, respectively. We assume a perfectly competitive market where each firm considers region A or B for its location. The objective of the firm when making a decision to locate in region A or B is to maximize the private net present value $N P V_{j}$, defined as the net present value (NPV) that the firm experiences

(C) Southern Regional Science Association 2010. 
under free-market conditions, taking into consideration all the private benefits versus all the private costs. The firm will enter the market in either region A or B only if it can achieve a positive NPV. The firm actually decides concurrently whether to operate $(N P V>0)$ and where to locate $\left(M A X N P V_{j}\right)$.

For analytical purposes, let us make the simplistic assumption that the NPV can be disaggregated into two parts: one part is determined by the specific technological factors of the firm or the sector and the other part depends on location factors. Let $N P V_{\text {basic }}$ represent that part of the NPV that is determined by the specific characteristics of the firm or the sector, such as production technology, production factors, and so on. Now, let $\sum_{i=1}^{t} N P V_{j}\left(X_{j i}\right)$ represent that part of the NPV that depends on location factors.

Although this is a static model, the NPV can be evaluated at a given point in time as a function of the expected values of future parameters. For the sake of simplicity, we do not assume any drastic changes in technological factors in the future, nor do we assume that the same changes occur in all regions.

As we stated previously, $\sum_{i=1}^{t} N P V_{j}\left(X_{j i}\right)$ represents that part of the NPV that is attributable to regional factors, where $X_{j i}$ represents variables that affect the NPV, and whose values are different in each region, such as prices, agglomeration, infrastructure, and so on; $i$ represents the index for each variable, $i=1 \ldots . t$; and $j$ represents the region index $j=\{\mathrm{A}, \mathrm{B}\}$. Therefore,

$$
N P V_{j}^{\text {private }}=N P V_{\text {basic }}+\sum_{i=1}^{t} N P V_{j}\left(X_{j i}\right) .
$$

For the sake of simplification, let us define $W_{i}$ as the relative weight of influence of variable $X_{j i}$. The location decision is based on the following equation:

$$
N P V_{j}^{\text {private }}=N P V_{\text {basic }}+\sum_{i=1}^{t} W_{i} X_{j i}
$$

Given that $\mathrm{NPV}_{\text {basic }}$ is identical for both regions, the firm aspires to maximize the following expression:

$$
Z P_{j}=\sum_{i=1}^{t} N P V_{j}\left(X_{j i}\right)=\sum_{i=1}^{t} W_{i} X_{j i},
$$

where $Z P_{j}$ is the "private score" of region $j$ and reflects the contribution of the characteristics of region $j$ to the NPV of any given firm in the region - that is, as perceived by the investors who have to make a location decision based on facts such as the influence of infrastructure in the region, the availability of a labor force, the distance from other regions, the cost of land, and so on. The "private score" of region $j$ therefore represents the economic benefits that can be gained by the firm as a consequence of the specific qualities of this region. 
In more traditional forms of production functions, the "private score" of a region would be reflected by additional variables or by changes in the parameters of existing variables. For example, some production functions include local infrastructure as an additional production factor. In other cases, production functions can have different coefficients for labor and capital in different locations or different constant parameters, which reflect the regional influence on the availability of a labor force, public services, and so on.

We normalize the value of each $X_{j i}$ in region B to one, so that the value of the variable in region $\mathrm{A}$ reflects the relative advantage of region $\mathrm{A}$ for each of the variables. We have selected five main factors that influence the score $Z P_{j}$ and divided them into two groups: exogenous and endogenous factors. The exogenous factors are represented by variables that are assumed to be determined or at least heavily influenced by forces that are external to a free market - mainly those of public policy such as infrastructure quality, labor-force quality, and accessibility to central amenities. The endogenous factors are represented by variables that are determined for each region as a function of the number of firms in the region: agglomeration economies and prices of production factors.

It is assumed that an increase in the number of firms in a region increases agglomeration economies and therefore increases the productivity of each firm in the region (see Arnott, 1979; Henderson, 1983, 1986; Nakamura, 1985; Goldstein and Gronberg, 1986; Catin, 1991, 1995; Ciccone and Hall, 1996; Davis and Weinstein, 1999).

We define $y$ as the ratio: $\frac{n_{A}}{n_{B}}$, where $n_{A}$ and $n_{B}$ reflect the number of firms in regions A and $\mathrm{B}$, respectively (as defined above, $n_{A}>n_{B}$ ). We also assume that the contribution of agglomeration economies, $P E$, increases at a decreasing rate, as represented by

$$
P E_{A}=(y)^{\alpha}, \quad 0<\alpha<1,
$$

where $P E_{A}$ indicates the relative advantage of region $\mathrm{A}$ in relation to region $\mathrm{B}$ resulting from the positive effects of agglomeration.

As the number of firms in the region rises, the prices of production factors, $P P$, such as rents, wages, and other production factors, in the region also rise (see Mera, 1973; Conrad, 1997; Mitra, 1999; Verhoef, 2000). We assume that prices increase at an increasing rate, as represented by the following function:

$$
P P_{A}=y^{\beta^{p}}, \quad \beta^{p}>12
$$

where $\beta^{p}$ is the elasticity of prices in relation to the number of firms, defined as the percentage change in price induced by a percent change in the number of firms. Here the $P P_{\mathrm{A}}$ stands for the relative prices in region $\mathrm{A}$ as compared to those in region $\mathrm{B}$.

(C) Southern Regional Science Association 2010. 


\section{FIGURE 1: Equilibrium under Free Market and Social Optimum Considerations}

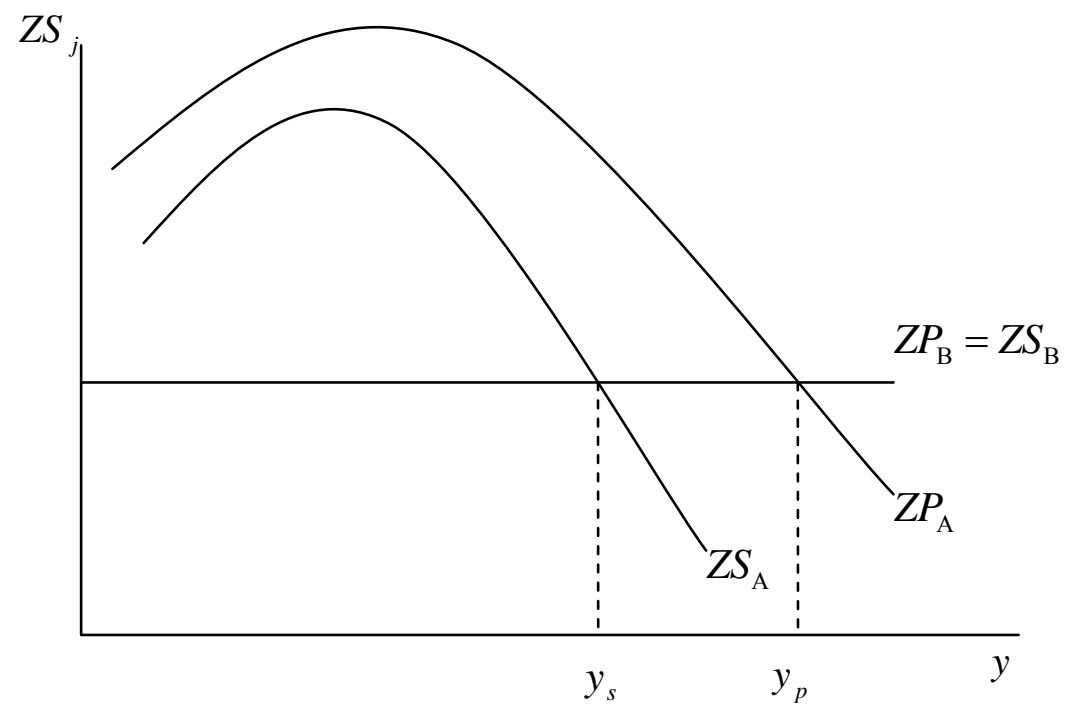

\subsection{The Free Market Solution}

We have shown that in a system with two regions, A and B, a free market leads to a finite ratio $y$. The score under free-market conditions is defined for each region as:

$$
\begin{aligned}
& Z P_{\mathrm{A}}=\text { const }_{\mathrm{A}}+W_{P E} y^{\alpha}-W_{P P} y^{\beta^{p}} \\
& Z P_{\mathrm{B}}=\text { const }_{\mathrm{B}}+W_{P E} 1^{\alpha}-W_{P P} 1^{\beta^{p}},
\end{aligned}
$$

where the const $_{j}$ is determined by all exogenous variables - infrastructure quality, labor-force quality, and accessibility to central amenities - and stands for the relative advantage of region A as compared to region B. $W_{P E}$ and $W_{P P}$ are the weights of the two parts of the NPV function.

Under free and competitive market conditions, the ratio between the number of firms in Region A and in Region B reaches equilibrium at $y_{p}$, as shown in Figure 1. This ratio represents a stable system equilibrium, where every shift away from it creates an advantage for either A or $\mathrm{B}$, causing firms to relocate in an effort to re-achieve equilibrium.

\subsection{The Social Optimum}

We show that a market failure occurs in the location of firms under free-market conditions. When a firm locates in a region, congestion increases, air pollution worsens, the costs of public infrastructure rise, the inequality in income distribution of the population increases, and so on. These are external centrifugal forces that are not expressed in the price mechanism perceived by the private investor. Consequently, they are not taken into account by the firm. The social optimum should therefore consider all positive and negative externalities created by the firms locating in a region. If done this way, the social optimum would reflect the best distribution 
of firms across the regions, a distribution that would bring the maximum benefit to society as a whole and not only to investors.

Let us define $Z S_{j}$ as the social score of region $j$. It is influenced by the social prices, $P S_{j}=(y)^{\beta^{s}}$, where $\beta^{s}$ represents the social elasticity of prices to the number of firms, and $\beta^{s}>\beta^{p}>1$. PS reflects the total cost to the economy based on the location of firms in a region and includes cumulative externalities costs in addition to PP, the cost reflected in the market prices. Actually, from a social perspective, when making its location decision a firm should consider the full cost to the economy, including the costs reflected in market prices such as rents and labor, but also the costs of the externalities like congestion and pollution which are not necessarily reflected in market prices. Thus, to achieve efficiency, the optimal location decision should be made according to $P S$ and not $P P$. Equation 2 above should now be replaced by:

$$
Z S_{\mathrm{A}}=\text { const }_{\mathrm{A}}+W_{P E} y^{\alpha}-W_{P P} y^{\beta^{S}}
$$

where $Z S_{A}$ is actually the real score of region A from an economic point of view because it includes the real prices to the economy, which are different from the private prices reflected in the market.

The addition of social costs $\left(\beta^{s}>\beta^{p}\right)$ leads to the result that at any given value of $y$, $Z S_{\mathrm{A}}<Z P_{\mathrm{A}}$, so the social equilibrium $y_{\mathrm{S}}$ is lower than the private equilibrium $y_{p}$, as can be seen in Figure 1, which illustrates the existence of a significant market failure. The fact that the free market does not assume social costs leads to an equilibrium that discriminates against the peripheral region. This type of market failure is caused by the gap between social and free market optimums (assuming at this stage that there is no price for government intervention), independent of the gap between the levels of economic activity in the regions. Actually, a market failure may occur when both regions have an equal number of firms at the free market optimum. The social optimum implies a higher number of firms in one of the regions. In concrete terms, we can achieve the social optimum with a higher number of firms in core region A.

The model above is described in full details in Malul and Bar-El (2009). In the next section, we add interregional mobility costs to the model and assess its impact on the gap between the free-market optimum and the social optimal regional distribution of firms.

\subsection{Government Intervention}

We assume that the government's objective is to lead the economy to a spatial structure $y_{s}$ that maximizes social welfare. Thus, the government needs to encourage firms to apply the social score as their business goal in the private market. Assuming at this stage that public intervention has a zero cost, the government endeavors to lead to a change in $Z P_{j}$ so that it attains $Z S_{j}$.

We show that if the government adopts a strategy that changes the const ${ }_{j}$ (by adopting a policy of infrastructure improvement in the periphery, improving educational services, etc.) it could actually effect a permanent and fundamental change in the equilibrium, possibly bringing the economy to an optimum $y_{s}$. Government intervention in the market is not regularly required 
because it creates a permanent, competitive advantage for region $\mathrm{B}$, the periphery. This equilibrium is therefore stable. It can be said that under specific conditions there will even be a Pareto improvement in the economy. Similar results by Kim et al. (2003) and Bar-El (2006) suggest that a more egalitarian spread of education (and other regional factors) could lead to a diminution of interregional gaps.

\subsection{Cost-Benefit}

Does resolving the market failure necessarily improve the welfare of the market? In order to answer this question, we must examine whether the total welfare change that results from the resolution of the market failure is greater than the costs to welfare of the government intervention. Therefore, the intervention can be justified only if:

$$
R\left(y_{s},\left(I\left(y_{p} \rightarrow y_{s}\right)\right)>R\left(y_{p}\right)\right.
$$

where $R\left(y_{p}\right)$ is the welfare under a free market, and $I\left(y_{p} \rightarrow y_{s}\right)$ is the cost of the public policy that needs to be implemented in order to reach $y_{s}$.

If inequality does arise, then the government should intervene as suggested above. Based on this condition, there can only be two options for conducting public policy-to intervene or not. Although we refer to the principles of the evaluation of policy intervention, we should mention that the social discount rate may be different from the discount rate in the private sector (see Rosen, 1995). In addition, the short-run social discount rate may be higher than the long-run rate (see Cropper, Aydede, and Portney, 1992).

Assuming that the cost of changing the const term can be divided and that the improvement of the relative advantage of one region over the other also can be divided, the following interim solution can be attained. Given that the market failure increases at accelerated rates, the social cost at the margins of $y_{p}, y_{p}-\varepsilon$ is greater than the social cost at the margins of $y_{s}, y_{s}+\varepsilon$. In contrast, the marginal social cost for changing const ${ }_{\mathrm{A}}$ increases consistently, and this could lead to an interim solution. When the government intervenes to reduce the gap between $y_{p}$ and $y_{s}$, welfare would increase because the market failure is reduced, but the cost of intervention, $I$, would cause a welfare decrease. Therefore, intervention should be invoked as follows. As long as the marginal utility (the increase in welfare resulting from the reduction of the market failure, which is a decreasing marginal utility) is higher than the marginal cost (the decrease in welfare resulting from the cost of intervention, which is an increasing marginal cost), public intervention for the decrease of the market failure is efficient, as shown in Figure 2.

As can be seen in Figure 2, the government should lead the firms to the new equilibrium $y_{s}^{m}$, as modified for the cost of intervention. The optimal expenditure will be: $I^{*}=f\left(y_{s}^{m}-y_{p}\right)$, where $I^{*}$ is the optimal scope of cost for government intervention. Thus, the new social score $\left(Z S_{A}^{m}\right)$ should satisfy the following condition- $Z S_{A} \leq Z S_{A}^{m} \leq Z P_{A}$. We can see in Figure 3 that if the optimal gap between the core and the periphery is higher than the free market solution, it is also smaller than the optimal solution when assuming a zero cost of intervention.

(C) Southern Regional Science Association 2010. 
FIGURE 2: Optimal Scope of Government Intervention

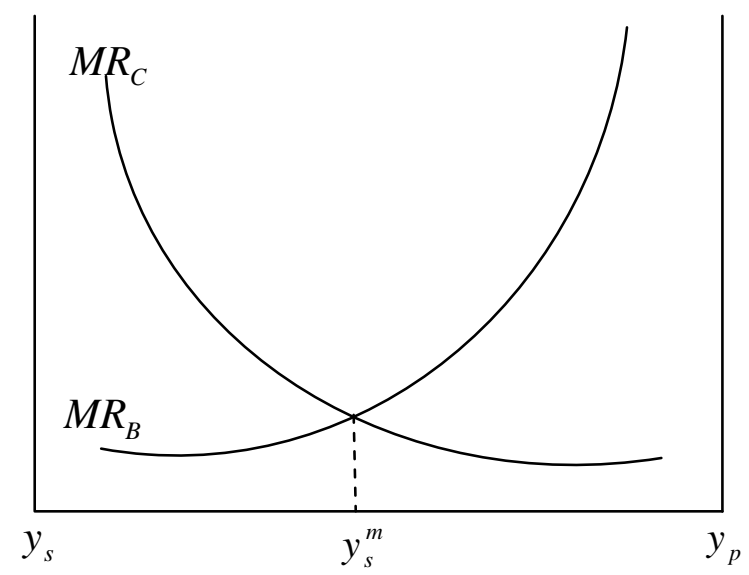

FIGURE 3: Optimal Solution Including the Cost of Intervention

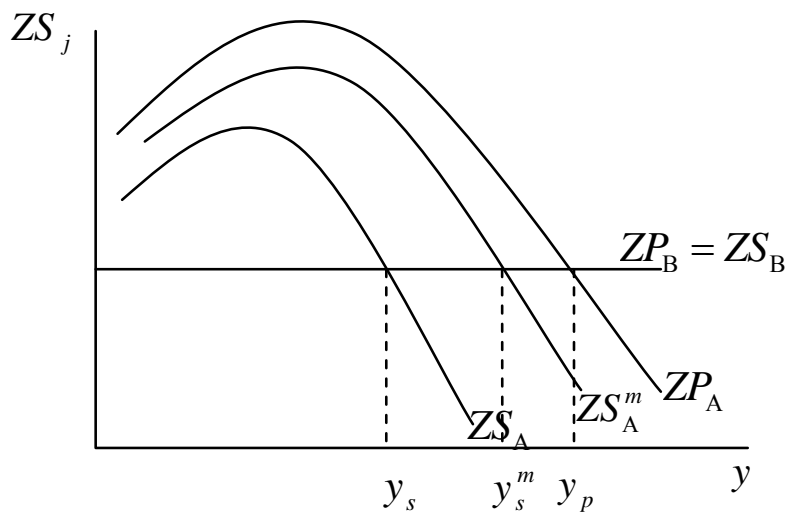

\subsection{Interregional Mobility}

Up to this point the model has been based on the unstated assumption that all production factors are immobile. Now, we weaken this assumption and assume that some of the production factors are mobile.

Assume that the production function is comprised of two types of production factors, immobile and mobile, so that

$$
Y=f(I M O B, M O B),
$$

where $Y$ is output, $I M O B$ is immobile production factors (such as land), and $M O B$ is mobile production factors (primarily capital and labor force, although labor force may also be immobile to some extent). We note that entrepreneurship can also be considered to be mobile (to some extent), but we do not include it here since we consider it endogenous - the decision of locating in region $\mathrm{A}$ or $\mathrm{B}$ is actually a decision of the entrepreneur to move his or her activity to region $\mathrm{A}$ or B.

(C) Southern Regional Science Association 2010. 
The firms use a certain share of each production factor, reflecting the production function of the firms. We define $\psi$ as the proportion of use of the mobile production factors. $1-\psi$ is then the proportion of use of the immobile production factors. We assume that these proportions are constant for all firms and do not depend upon prices.

We define the cost of mobility as $1-\tau$, applying iceberg shipping costs; that is, when moving a product or a factor from one region to another, only a fraction of it $\tau$ arrives at its destination. This cost was presented in a regional model for the first time by Krugman (1991) and in later studies conducted by Baldwin (1999), Lanaspa and Sanz (2001a, 2001b), Hu (2002), and Hadar and Pines (2004). It is well known that when applied to explicit distances the iceberg assumption has some drawbacks in that the behavior of transport costs predicted by icebergs does not match recent empirical observations (see McCann, 2005). As in much of the new economic geography literature, iceberg transportation costs are used here out of tractable convenience. Since the model here has only two regions, explicit distances are not needed, which gives some justification for this assumption.

We assume that decreasing mobility costs would encourage commuting as an alternative to migration. In our model, decreasing mobility costs influence the ratio of the prices between the regions as well as the constant term in our equation as follows.

\subsubsection{Effect on relative prices of production factors}

We define $P P M^{n}$ as the relative prices of production factors, adjusted for mobility costs:

$$
P P M^{n}=(1-\psi) y^{\beta^{p}}+\psi y^{(1-\tau) \beta^{p}} .
$$

The basic model assumes an extremely high level of mobility costs (a value of 1 for the term of 1$-\tau$ ), meaning that no production factor is "imported" from another region (the entire iceberg would "melt" in the process of transition from one region to another). Therefore, the cost of the local production factors in the region would increase as indicated by the exponential term $\beta^{p}$. A low level of mobility costs (a low value of $1-\tau$ ) leads to a lower price of "imported" production factors from another region (a smaller part of the iceberg is lost in the transition from one region to another). An extreme case would be zero mobility costs, which would completely annul the price effect. For example, if the production factor is labor, a low or zero cost of mobility from one region to another actually means that the ability of a region to draw workers from another region is unlimited. Thus the cost of labor would not increase as a function of an increase in economic activity in the region.

\subsubsection{Effect on the constant term}

The mobility cost affects the constant term, const $_{\mathrm{A}}$. When the mobility cost is relatively low, the advantage that stems from the higher value of the constant term at the center is less significant. The relative advantage in each of the parameters that affect the constant is therefore smaller.

$$
\operatorname{const}_{\mathrm{A}}^{m}=\sum_{i=1}^{t_{c}} W_{i} X_{\mathrm{A} i}^{(1-\tau)},
$$

where const $_{\mathrm{A}}^{m}$ is the modified constant and $t_{c}$ indicates the number of parameters included in the constant term. A lower cost of mobility would provide the peripheral region with better access to 
services offered at the core region and improve its score. Theoretically, a zero mobility cost $(\tau=1)$ would eradicate the entire advantage of the core region that results from offering better amenities (the constant term would be equal in both regions).

\subsection{Equilibrium Including Mobility Cost}

We define const $_{j}^{m}$ as the modified constant term of region $j$, taking into account the mobility costs, const $_{\mathrm{A}}^{m}<$ const $_{\mathrm{A}}$. The free market adjusted score $Z P M_{j}$ is $Z P M_{j}=$ const $_{j}^{m}+W_{P E} P E_{j}^{n}-W_{P P} P P M_{j}^{n}$. The mobility cost $(1-\tau)$ between regions is positive since $0<\tau<1$, and a portion of the production factors is mobile, $0>\psi>1$. In this case, $P P_{j}>P P M_{j}>1$ for each value of $y$. This means that the ratio of prices adjusted for the cost of mobility is greater than one, yet smaller than the same ratio of prices in the case of no mobile production factors, as presented in the basic model. The adjusted scores for mobility costs are:

$$
\begin{gathered}
Z P M_{\mathrm{A}}=\text { const }_{\mathrm{A}}^{m}+W_{P E} y^{\alpha}-W_{P P}\left((1-\psi) y^{\beta^{p}}+\psi y^{(1-\tau) \beta^{p}}\right) \\
Z P M_{\mathrm{B}}=\text { const }_{\mathrm{B}}^{m}+W_{P E} 1^{\alpha}-W_{P P} 1^{\beta^{p}}
\end{gathered}
$$

where $Z P M_{\mathrm{A}}$ and $Z P M_{\mathrm{B}}$ reflect the scores that are modified to the mobility costs of region $\mathrm{A}$ and $\mathrm{B}$, respectively.

As illustrated in Figure 4, higher mobility (lower mobility costs) of production factors may have two contradictory influences upon the location decision. Figure 4 shows the difference between equilibrium in the basic model in which the unstated assumption is $\psi=0$, or an iceberg value $\tau=0$, and the current expansion in which $1>\psi>0$ and $1>\tau>0$.

FIGURE 4: Private Market Equilibrium Including Mobility Cost

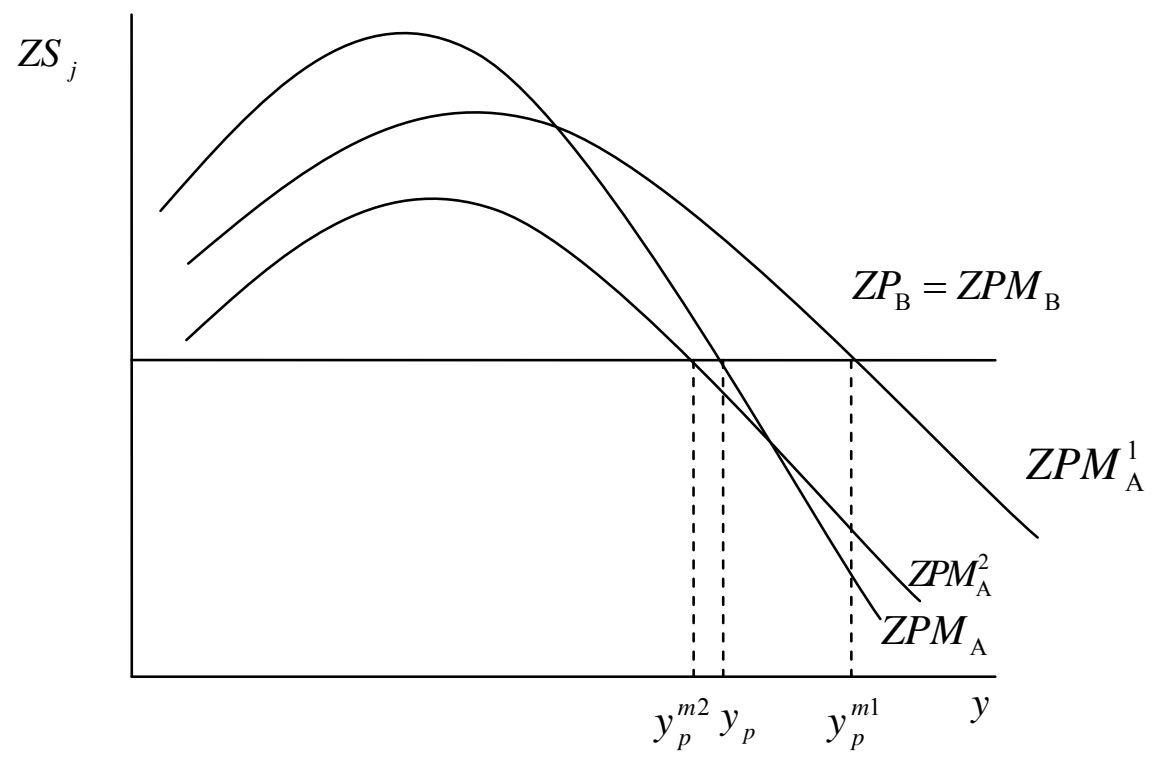

c) Southern Regional Science Association 2010. 


\section{In Figure 4:}

1. The curve of $Z P_{\mathrm{A}}$ shows the equilibrium in the case of total immobility as a result of externally imposed constraints $(\psi=0)$ or as a result of extremely high mobility costs $(\tau=0)$. Equilibrium in this case is proportionate, $y_{p}$, as shown in the basic model.

2. The curve of $Z P M_{\mathrm{A}}^{1}$ shows the equilibrium if the effect on prices (a slope that is less steep) is greater than the effect on the constant (vertical decrease). The equilibrium in that case would be $y_{p}^{m 1}$, which is larger than $y_{p}$ where there is no possibility of mobility of production factors. In this case, labor can commute from the periphery to the core region at some cost $(1>\tau>0)$, but for many reasons (e.g., distances are too great) the periphery cannot enjoy most of the amenities in the core region, which are reflected in const. This is demonstrated by the fact that the vertical down movement of the curve is relatively small, while the decrease in the slope of the curve is quite significant. The ability of the core region to attract production factors from the periphery, coupled with the inability of the periphery to enjoy a large part of the advantages of the core region, leads to an increasing concentration of economic activity in the center.

In that case, we can expect that even if the economic activity (GDP) is lower with the potential of increasing inequality, the level of income (GNP) of the population in the periphery may increase as a consequence of more open accessibility to employment in the core region, thus decreasing inequality. If this happens, the question of the contribution to the social optimum remains open - higher mobility facilitates a more efficient economic system and also enables higher levels of income for the population as a whole. However, it may increase interregional inequality when the ability of the labor force in the periphery to work in the core region is limited to workers at higher levels.

3. The curve of $Z P M_{\mathrm{A}}^{2}$ shows the equilibrium if the effect on prices (a slope that is less steep) is smaller than the effect on the constant (vertical decrease). The equilibrium in that case is at $y_{p}^{m 2}$, which is smaller than $y_{p}$. In this case, the periphery can enjoy many of the amenities of the center (e.g., by using an advanced communications system); however, the center cannot attract a significant portion of labor from the periphery. The ability of the periphery to enjoy some of the advantages of the core region while still benefiting from a relatively cheap labor supply increases its attractiveness for economic activity.

The new equilibrium takes into consideration that the mobility effect can have a higher or lower proportion than the one in the basic model where no mobility is allowed, depending on the leading type of the mobility effect. The new curve is actually a combination of the two curves in the figure.

In the same way as above, it can be demonstrated that the modified optimal ratio $y_{s}^{m}$ can be greater, lower, or the same in relation to the previous situation $y_{s}$ with no mobility at all. Nonetheless, it is necessarily lower than the one that the free market achieves as derived from the following inequality: $Z S M_{\mathrm{A}}\left(y_{p}^{m}\right)<Z P M_{\mathrm{A}}\left(y_{p}^{m}\right)=Z P M_{\mathrm{B}}\left(y_{p}^{m}\right)$, where $Z S M_{\mathrm{A}}$ reflects the social relative score of region $\mathrm{A}$, which is modified to the mobility costs. 
Tabuchi and Thisse (2006) found that dispersion or agglomeration emerges when the commuting cost is high or low, respectively. For intermediate values, the set of equilibria is much richer in that they typically involve regional specialization and urban hierarchy. Gianmarco and Robert-Nicoud. (2006) have shown that the market outcome is efficient only in extreme situations, when forward and backward linkages are either very strong or very weak and when trade costs are either very small or very large. For intermediate situations, the market is usually inefficiently biased against agglomeration.

\section{CONCLUSION}

The introduction of higher levels of mobility does not eliminate the market failure that results from the fact that the business market does not acknowledge some of the implications of increasing economic activity in a region. However, if the improvement in mobility costs takes place concurrently with the changing of regional constants, market failure could be eliminated.

When the leading impact of improved mobility is on the constant term, meaning a better ability of the periphery to enjoy the advantages of the core region, the gap is certainly smaller, decreasing distortions and enabling a higher level of economic activity in the periphery. When the leading impact of improved mobility is on the cost of production factors, the result is a higher concentration of economic activity in the core region; still, the change in the gap between market equilibrium and social equilibrium is not quite clear. On one hand, the level of economic activity in the periphery is lower, increasing inequality, but on the other hand the level of income of the population in the periphery may increase as a consequence of more open accessibility to employment in the core region, decreasing the inequality. Here, we face the same type of distinction as the one between GDP and GNP, but on a regional basis. Just as GDP may decrease and GNP may increase simultaneously, on a regional basis, we may face a situation where economic activity decreases and the situation of the population improves as a result of increased employment opportunities at the center. If this occurs, the question of the contribution to the social optimum remains open - higher mobility facilitates a more efficient economic system and enables higher levels of income for the population as a whole. Still, it may increase interregional inequality when the ability of the labor force in the periphery to work in the core region is limited to workers at higher levels.

\section{REFERENCES}

Abdel-Rahman, Hesham M. and Alex Anas. (2004) "Theories of Systems of Cities," Chapter 52 in J. Vernon Henderson and Jacques-François Thisse (eds), Handbook of Regional and Urban Economics, Vol. 4. Elsevier: Amsterdam, pp. 2293-2339.

Arnott, Richard. J. (1979) “Unpriced Transport Congestion,” Journal of Economic Theory, 21, 294-316.

Baldwin, Richard. E. (1999) "The Core-Periphery Model with Forward-Looking Expectations," NBER Working Paper No. 6921.

Baldwin, Richard. E. and Philippe Martin. (2004) "Agglomeration and Regional Growth," Chapter 52 in J. Vernon Henderson and Jacques-François Thisse (eds), Handbook of Regional and Urban Economics, Vol. 4. Elsevier: Amsterdam, pp. 2671-2711.

Bar-El, Raphael. (2006) "Inter-regional Labor Market Equilibrium: Another Pattern of Spatial Mismatch," Annals of Regional Science, 40, 393-405.

(C) Southern Regional Science Association 2010. 
Bar-El, Raphael and Dafna Schwartz. (2006) "Regional Development as a Policy for Growth with Equity - The State of Ceara (Brazil) as a Model," Progress in Planning, 65, 125200.

Catin, Maurice (1991) “Économies d'Agglomération et Gains de Productivité," Revue d’Économie Régionale et Urbaine, 5, 567-598.

-. (1995) "Productivité, Économies d'Agglomération et Métropolisation," Revue d'Économie Regionale et Urbaine, 4, 663-681.

Ciccone, Antonio and Robert E. Hall. (1996) "Productivity and the Density of Economic Activity," American Economic Review, 86, 54-70.

Conrad, Klaus. (1997) “Traffic, Transportation, Infrastructure and Externalities: A Theoretical Framework for a CGE Analysis,” Annals of Regional Science, 31, 369-389.

Cropper, Maureen L., Sema K. Aydede, and Paul R. Portney. (1992) "Rates of Time Preference for Saving Lives," American Economic Review, 82, 469-472.

Davis, Donald R. and David E. Weinstein. (1999) "Economic Geography and Regional Production Structure: An Empirical Investigation," European Economic Review, 43, 379407.

Dohse, Dirk. (1998) "Infrastructure Provision and Locational Efficiency in a Federation: A Numerical Approach,” Papers in Regional Science, 77, 241-263.

Fujita, Masahisa and Hesham M. Abdel-Rahman. (1993) "Specialization and Diversification in a System of Cities," Journal of Urban Economies, 33, 189-222.

Gianmarco I. P. Ottaviano and Frédéric Robert-Nicoud. (2006) “The 'Genome' of NEG Models with Vertical Linkages: A Positive and Normative Synthesis," Journal of Economic Geography, 6, 113-139.

Goldstein, Gerald S. and Timothy J. Gronberg. (1986) "Economies of Scope and Economies of Agglomeration," Journal of Urban Economics, 16, 91-104.

Hadar, Yossi and David Pines. (2004) "Population Growth and its Distribution between Cities: Positive and Normative Aspects," Regional Science and Urban Economics, 34, 125-154.

Helsley, Robert W. and William C. Strange. (1990) "Matching and Agglomeration Economies in a System of Cities," Regional Science and Urban Economics, 20, 189-212.

Henderson, J. Vernon. (1983) “Industrial Bases and City Sizes,” American Economic Review, 73, $164-168$.

(1986) "Efficiency of Resource Usage and City Size," Journal of Urban Economics, 19, $47-70$.

$\mathrm{Hu}$, Dapeng. (2002) "Trade, Rural-Urban Migration, and Regional Income Disparity in Developing Countries: A Spatial General Equilibrium Model Inspired by the Case of China," Regional Science and Urban Economics, 32, 311-338.

Kim, Euijune, Euijune Kim, Sung Woong Hong, and Soo Jung Ha. (2003). "Impacts of National Development and Decentralization Policies on Regional Income Disparity in Korea," Annals of Regional Science, 37, 79-91.

(C) Southern Regional Science Association 2010. 
Krugman, Paul. (1991) "Increasing Returns and Economic Geography," Journal of Political Economy, 3, 483-499.

Lanaspa, Luis Fernando and Fernando Sanz. (2001a) "Multiple Equilibria, Stability, and Asymmetries in Krugman's Core-Periphery Model," Papers in Regional Science, 80, 425-438.

—. (2001b) "The Public Sector and Core-Periphery Models," Urban Studies, 38, 16391649.

McCann, Philip. (2005) "Transport Costs and New Economic Geography," Journal of Economic Geography, 5, 305-318.

Malul, Miki and Raphael Bar-El. (2009) “The Gap Between Free Market and Social Optimum in The Location Decision of Economic Activity," Urban Studies, 46, 2045-2059.

Mera, Koichi. (1973) "On the Urban Agglomeration and Economic Efficiency," Economic Development and Cultural Change, 21, 309-324.

Mitra, Arup. (1999) "Agglomeration Economies as Manifested in Technical Efficiency at the Firm Level," Journal of Urban Economics, 45, 490-500.

Nakamura, Ryohei. (1985) "Agglomeration Economies in Urban Manufacturing Industries: A Case of Japanese Cities," Journal of Urban Economics, 17, 108-124.

Rosen, Harvey S. (1995) Public Finance, $4^{\text {th }}$ ed. Richard D. Irwin, Inc.

Tabuchi, Takatoshi and Jacques-François Thisse. (2006) "Regional Specialization, Urban Hierarchy, and Commuting Costs," International Economic Review, 47, 1295-1317.

Verhoef, Erik T. (2000) "The Implementation of Marginal External Cost Pricing in Road Transport: Long Run vs. Short Run and First-Best vs. Second-Best," Papers in Regional Science, 79, 307-332.

(C) Southern Regional Science Association 2010. 